\title{
Thermochemical Modeling of the Uranium-Cerium-Oxygen System
}

\author{
Stewart Voit and Ted Besmann, Oak Ridge National Laboratory
}

\section{Introduction}

The objective of the Fuel Cycle R\&D Program, Advanced Fuels campaign is to provide the research and development necessary to develop low loss, high quality nuclear fuels for ultra-high burnup reactor operation. Primary work in this area will be focused on the ceramic and metallic fuel systems. The goal of the current work is to enhance the understanding of ceramic nuclear fuel thermochemistry to support fuel research and development efforts.

The thermochemical behavior of oxide nuclear fuel under irradiation is dependent on the oxygen to metal ratio (O:M). In fluorite-structured fuel, the actinide metal cation is bonded with $\sim 2$ oxygen atoms on a crystal lattice and as the metal atoms fission, fission fragments and free oxygen are created. The resulting fission fragments will contain some oxide forming elements, however these are insufficient to bind to all the liberated oxygen and therefore, there is an average increase in O:M with fuel burnup. Some of the fission products also form species that will migrate to and react with the cladding surface in a phenomenon known as Fuel Clad Chemical Interaction (FCCl). i,i Cladding corrosion is life-limiting so it is desirable to understand influencing factors, such as oxide thermochemistry, which can be used to guide the design and fabrication of higher burn up fuel.

A phased oxide fuel thermochemical model development effort is underway within the Advanced Fuels Campaign. First models of binary oxide systems are developed. For nuclear fuel system this means $\mathrm{U}-\mathrm{O}$ and transuranic systems such as $\mathrm{Pu}-\mathrm{O}, \mathrm{Np}-\mathrm{O}$ and $\mathrm{Am}-\mathrm{O}$. Next, the binary systems will be combined to form pseudobinary systems such as U-Pu-O, etc. The model development effort requires the use of data to allow optimization based on known thermochemical parameters as a function of composition and temperature. Available data is mined from the literature and supplemented by experimental work as needed.

Due to the difficulty of performing fuel fabrication development with actinide materials, fundamental studies with uranium are performed using surrogate materials as stand-ins for transuranic elements. In most cases, cerium can be used as a suitable substitute for plutonium when performing O:M and sintering kinetics studies because of identical valence states. Differences exist between the magnitude of reported thermodynamic data of $(\mathrm{U}, \mathrm{Pu}) \mathrm{O}_{\mathrm{x}}$ and $(\mathrm{U}, \mathrm{Ce}) \mathrm{O}_{\mathrm{x}}$, however the change in oxygen potential versus O:M follows the same trend for both systems. Cerium is also a major fission product element, and thus understanding its behavior in fuel is an important issue as well. 


\section{CEF for $\mathrm{U}-\mathrm{Ce}-\mathrm{O}_{\mathrm{x}}$}

Thermochemical model optimization is performed using a Compound Energy Formalism (CEF) $)^{i i i}$ representation of the $\mathrm{U}-\mathrm{Ce}-\mathrm{O}_{\mathrm{x}}$ system. A three sublattice CEF model of the $\mathrm{UO}_{2 \pm x}$ system has been developed by Gueneau et al. ${ }^{\text {iv }}$ The uranium oxygen system fluorite structure phase has thermodynamic properties which are a function of O:M. Zinkevich et al. created a two sublattice CEF model for the $\mathrm{Ce}-\mathrm{O}$ system. ${ }^{v}$ Models for the $\mathrm{U}-\mathrm{O}$ and the $\mathrm{Ce}-\mathrm{O}$ systems adequately represent pure stoichiometric phases as well as non-stoichiometric oxides including vacancy and interstitial defects.

To develop a CEF model of the $\mathrm{U}-\mathrm{Ce}-\mathrm{O}_{\mathrm{x}}$ system, it is necessary to extend the present two sublattice $\mathrm{Ce}-\mathrm{O}$ model to include a third sublattice to facilitate combination with the three sublattice U-O model. The CEF approach for the U$\mathrm{Ce}-\mathrm{O}_{2 \pm x}$ system takes the following form.

$\left(\mathrm{Ce}^{+3}, \mathrm{Ce}^{+4}, \mathrm{U}^{+3}, \mathrm{U}^{+4}, \mathrm{U}^{+6}\right)_{1},\left(\mathrm{O}^{-2}, \mathrm{Va}\right)_{2},\left(\mathrm{O}^{-2}, \mathrm{Va}\right)_{1}$

The constituent species that comprise the sublattice system is given in Table 1 and is consistent with the formalism established by Gueneau et al. and Zinkevich et al. A graphical representation of the constituent species in a three sublattice framework is shown in Figure 1. Electroneutrality is maintained through various combinations of the species in Table 1. In the hyperstoichiometric region, oxygen interstitials are introduced on the anion sublattices and $\mathrm{U}^{+4}$ and $\mathrm{U}^{+6}$ on the cation sublattice with Ce largely +4 valence. Hypostoichiometry is accounted for through oxygen vacancies with the presence of predominantly $\mathrm{Ce}^{+3}, \mathrm{Ce}^{+4}$, or $\mathrm{U}^{+4}$ on the first sublattice.

Table 1. Sublattice constituent species

\begin{tabular}{lll}
\hline +3 Cation Valence & +4 Cation Valence & +6 Cation Valence \\
\hline$\left(\mathrm{Ce}^{+3}\right)_{1},\left(\mathrm{O}^{-2}\right)_{2},\left(\mathrm{O}^{-2}\right)_{1}$ & $\left(\mathrm{Ce}^{+4}\right)_{1},\left(\mathrm{O}^{-2}\right)_{2},\left(\mathrm{O}^{-2}\right)_{1}$ & $\left(\mathrm{U}^{+6}\right)_{1},\left(\mathrm{O}^{-2}\right)_{2},\left(\mathrm{O}^{-2}\right)_{1}$ \\
\hline$\left(\mathrm{Ce}^{+3}\right)_{1},\left(\mathrm{O}^{-2}\right)_{2},(\mathrm{Va})_{1}$ & $\left(\mathrm{Ce}^{+4}\right)_{1},\left(\mathrm{O}^{-2}\right)_{2},(\mathrm{Va})_{1}$ & $\left(\mathrm{U}^{+6}\right)_{1},\left(\mathrm{O}^{-2}\right)_{2},(\mathrm{Va})_{1}$ \\
\hline$\left(\mathrm{Ce}^{+3}\right)_{1},(\mathrm{Va})_{2},\left(\mathrm{O}^{-2}\right)_{1}$ & $\left(\mathrm{Ce}^{+4}\right)_{1},(\mathrm{Va})_{2},\left(\mathrm{O}^{-2}\right)_{1}$ & $\left(\mathrm{U}^{+6}\right)_{1},(\mathrm{Va})_{2},\left(\mathrm{O}^{-2}\right)_{1}$ \\
\hline$\left(\mathrm{Ce}^{+3}\right)_{1},(\mathrm{Va})_{2},(\mathrm{Va})_{1}$ & $\left(\mathrm{Ce}^{+4}\right)_{1},(\mathrm{Va})_{2},(\mathrm{Va})_{1}$ & $\left(\mathrm{U}^{+6}\right)_{1},(\mathrm{Va})_{2},(\mathrm{Va})_{1}$ \\
\hline$\left(\mathrm{U}^{+3}\right)_{1},\left(\mathrm{O}^{-2}\right)_{2},\left(\mathrm{O}^{-2}\right)_{1}$ & $\left(\mathrm{U}^{+4}\right)_{1},\left(\mathrm{O}^{-2}\right)_{2},\left(\mathrm{O}^{-2}\right)_{1}$ & \\
\hline$\left(\mathrm{U}^{+3}\right)_{1},\left(\mathrm{O}^{-2}\right)_{2},(\mathrm{Va})_{1}$ & $\left(\mathrm{U}^{+4}\right)_{1},\left(\mathrm{O}^{-2}\right)_{2},(\mathrm{Va})_{1}$ & \\
\hline$\left(\mathrm{U}^{+3}\right)_{1},(\mathrm{Va})_{2},\left(\mathrm{O}^{-2}\right)_{1}$ & $\left(\mathrm{U}^{+4}\right)_{1},(\mathrm{Va})_{2},\left(\mathrm{O}^{-2}\right)_{1}$ & \\
\hline$\left(\mathrm{U}^{+3}\right)_{1},(\mathrm{Va})_{2},(\mathrm{Va})_{1}$ & $\left(\mathrm{U}^{+4}\right)_{1},(\mathrm{Va})_{2},(\mathrm{Va})_{1}$ & \\
\hline
\end{tabular}




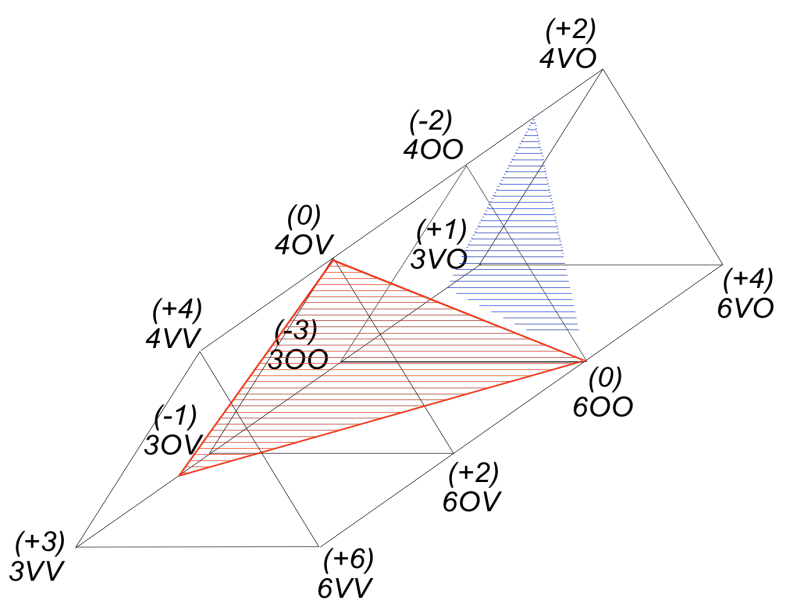

Fig. 1. Constituent species in three sublattice representation (Gueneau et al).

The relationship for the Gibbs free energy of $\mathrm{UCeO}_{2 \pm x}$ is constructed as follows:

$$
G=\sum_{i} \Omega_{i}{ }^{o} G_{\Omega_{i}}+\sum_{i} R T \ln \Omega_{i}+\sum_{i} \sum_{n} \Omega_{i}\left(1-\Omega_{i}\right)\left(1-\Omega_{i}\right)^{n} L_{n, i}
$$

where $\Omega_{i}$ is the site fraction for species on the primary, secondary, and tertiary sublattices, $G_{\Omega i}$ is the Gibbs free energy of the various species combinations on the sublattices, $R$ is the ideal gas law constant, $T$ is absolute temperature, and $L_{n, i}$ are the interaction parameters between different defect species.

\section{Oxygen potential measurement data}

Experimental data in the $\mathrm{UCeO}_{2 \pm x}$ is limited. This is demonstrated in Figure 2 which displays a plot of the composition, temperature, and O:M data points from the literature. From Figure 2 it can be seen that the compositional data are confined to a narrow range with no data points at low and high uranium content, very few points at low O:M values, and none at $\mathrm{O}: \mathrm{M}>2$. There is a slightly wider distribution of temperature data; however, experimental work has not been performed at high temperatures and moderate to low O:M.

The relationship between oxygen potential and O:M for $U_{1-y}, \mathrm{Ce}_{\mathrm{y}} \mathrm{O}_{2-\mathrm{x}}$ was evaluated by Markin and Crouch $^{\text {vi }}$ using a gas equilibrium method and a galvanic cell in the temperature range from $800-950^{\circ} \mathrm{C}$ where $0.10<y<0.75$. Their results display a continuous variation of oxygen potential versus O:M indicating a single phase region. Ducroux and Baptiste provide a consistent data set for $\mathrm{U}_{70}, \mathrm{Ce}_{30} \mathrm{O}_{2-\mathrm{x}}$ between $600-1000^{\circ} \mathrm{C}$ and they compare their results with those from Markin and Crouch as well as Hoch and Furman. vii The compositions differ slightly but the variation in slope of the oxygen potential curve follows the expected trend. The data from Hoch and Furman display large uncertainty so the data are not considered here. 


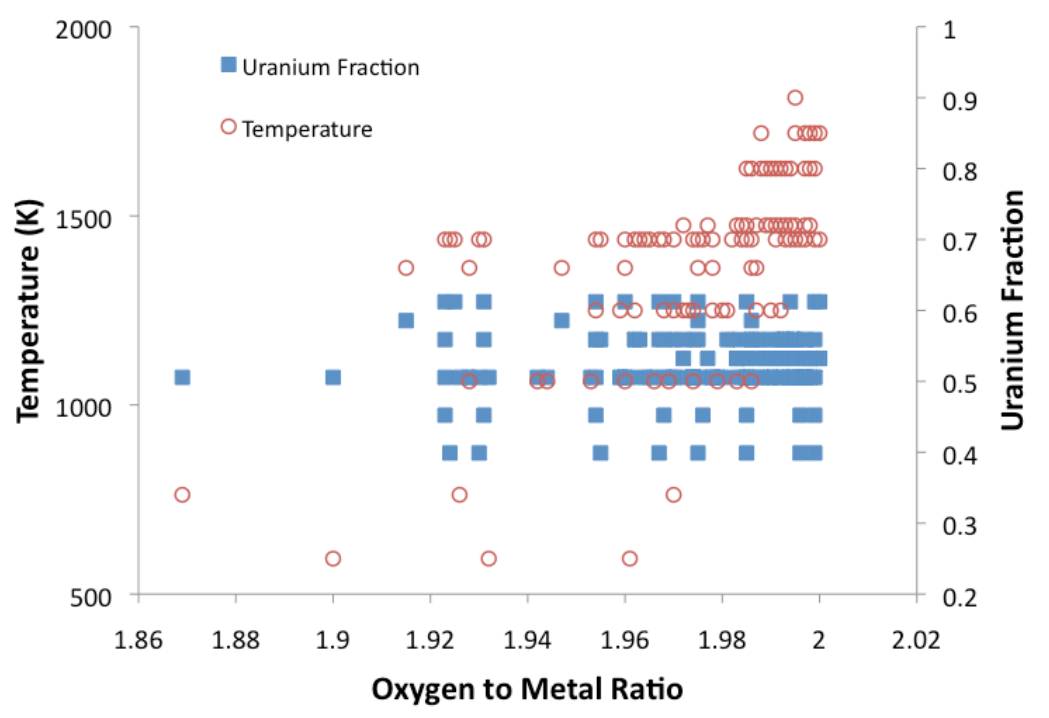

Fig. 2. $\mathrm{UCeO}_{x}$ Experimental Data Space.

Using a thermogravimetric method, Norris and Kay viii found similar results for $y=$ 0.148 and 0.282 in work that included X-ray Diffraction (XRD) data at $1123 \mathrm{~K}$. The oxygen potential versus O:M data correlate well with that of previous authors ${ }^{\mathrm{ix}, \mathrm{x}}$ for different cerium fraction $\left[{ }^{\mathrm{Ce}} /(\mathrm{U}+\mathrm{Ce})\right]$ and different temperatures. XRD results at $1123 \mathrm{~K}$ indicate a single phase solid solution with a linearly varying lattice parameter with O:M consistent with Markin and Crouch. However, samples that were quenched to room temperature show the presence of a second phase. Markin and Crouch suggests that the two-phase field begins with $y \geq 0.34$ but later work by Lorrenzelli provides evidence of second phase development at $\mathrm{y} \sim 0.2$.

Nagarajan et al. performed oxygen potential measurements on $U_{1-y}, \mathrm{Ce}_{\mathrm{y}} \mathrm{O}_{2-\mathrm{x}}$ for $\mathrm{y}$ $=0.2$ and 0.5 for $1073 \mathrm{~K}$ and $1173 \mathrm{~K} .{ }^{\mathrm{xi}}$ The authors used a gas equilibrium method to establish the oxygen potential versus temperature conditions and wet chemistry to determine the O:M. Oxygen potential data are plotted with respect to cerium valence and compared to results for plutonium valence in $\mathrm{U}_{1-\mathrm{y}}, \mathrm{Pu}_{\mathrm{y}} \mathrm{O}_{2-\mathrm{x}}$. It is expected that the data should follow the Markin-Mclver rule which states that the change in oxygen potential is correlated with the change in $y$ and is not related to the change in uranium content. The uranium is assumed to be a fixed +4 valence while the valence of the cerium (or plutonium) changes with y. Norris and Kay found that various models that are used to reconcile the data with respect to the Markin-Mclver rule are inadequate over the compositional space. Nagarajan et al. come to this same conclusion and further suggest that the relationship between oxygen potential and valence may be independent of composition. 


\section{Optimization}

The data from Markin and Crouch, Ducroux and Baptiste, and Norris and Kay were to fit zeroth and first order interaction parameters $\left(\mathrm{L}^{0}\right.$ and $\left.\mathrm{L}^{1}\right)$. As assumed by Gueneau et al. ${ }^{i v}$ the values for $L$ for $\left(\mathrm{Ce}^{3+}, \mathrm{U}^{4+}\right)_{1}\left(\mathrm{O}_{2}\right)_{2}(\mathrm{Va})_{1}$ were made equivalent to those for $\left(\mathrm{Ce}^{3+}, \mathrm{U}^{4+}\right)_{1}(\mathrm{Va})_{2}(\mathrm{Va})_{1}$, for interactions among the cations on that lattice. Similarly, the $\mathrm{L}$ values for $\left(\mathrm{Ce}^{4+}, \mathrm{U}^{4+}\right)_{1}\left(\mathrm{O}_{2}\right)_{2}(\mathrm{Va})_{1}$ were made equivalent to those for $\left(\mathrm{Ce}^{4+}, \mathrm{U}^{4+}\right)_{1}(\mathrm{Va})_{2}(\mathrm{Va})_{1}$. The software package FactSage ${ }^{\mathrm{xi}}$ was used for the optimization applying the Optisage module. Declared independent variables were temperature, total pressure, and composition with the dependent variable the log of the oxygen pressure as reported by Markin and Crouch, Norris and Kay, and Ducroux and Baptiste.

\section{Results}

The initial attempts to establish the coefficients and site fractions that lead to minimization of the Gibbs free energy were unsuccessful when considering the complete set of available data. As a result, an assessment was performed which would allow the grouping of data that was self-consistent. Based on this assessment, data from Markin and Crouch, Norris and Kay, and Ducroux and Baptiste was selected. It is difficult to plot the complete set of data and corresponding calculated fit on a single plot due to the number of degrees of freedom so a subset is chosen to illustrate the results.

Figure 3 shows a plot of the experimental data points for $\mathrm{U}_{70}, \mathrm{Ce}_{30} \mathrm{O}_{2-\mathrm{x}}$ at temperatures between $873 \mathrm{~K}$ and $1273 \mathrm{~K}$. Also shown for comparison is the calculated fit to the data based on the CEF optimization.

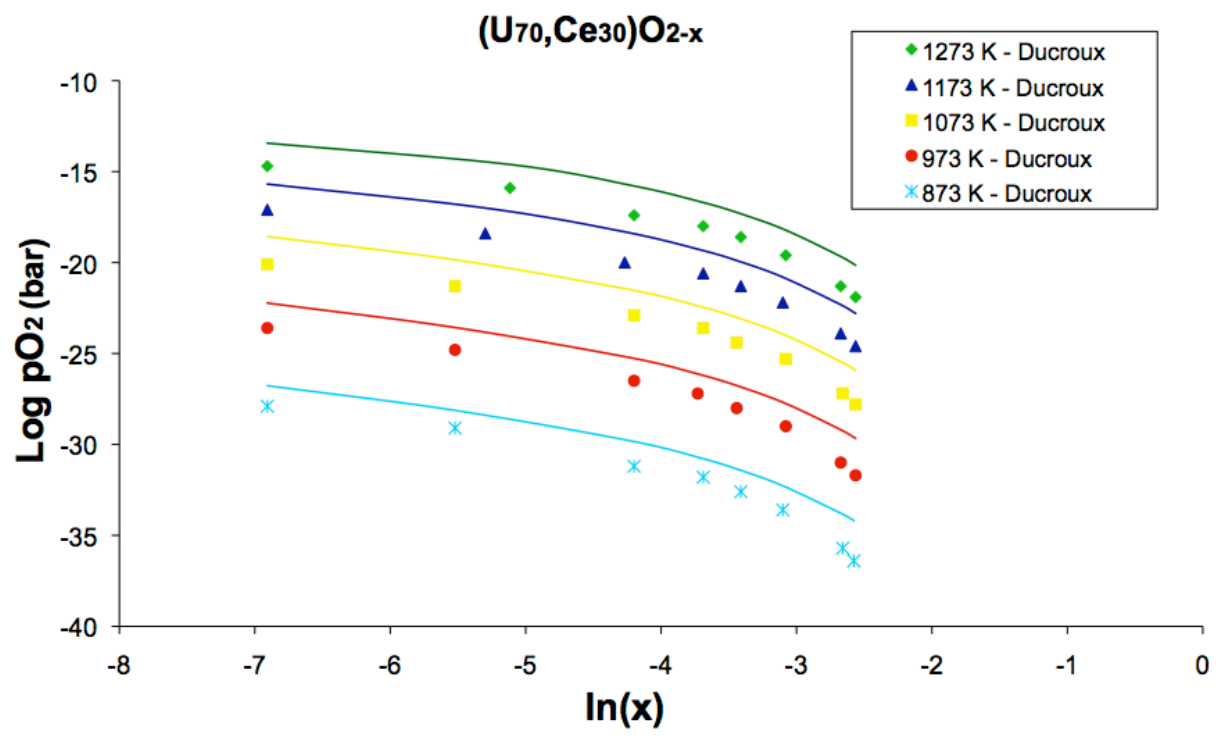

Fig. 3. Plot of the oxygen potential versus composition from experiment (data points) compared with results from an initial optimization of a CEF model for $\mathrm{UCe}_{2-\mathrm{x}}$ (solid lines). 
The calculation displays the correct trends and a reasonable fit to the data, however with data from a limited thermochemical space, convergence to a solution was not achieved. The deviation between the calculated and experimental values (residuals) is greater than desired, as can be seen in Figure 4 , and is consistent with the fit shown in Figure 3.

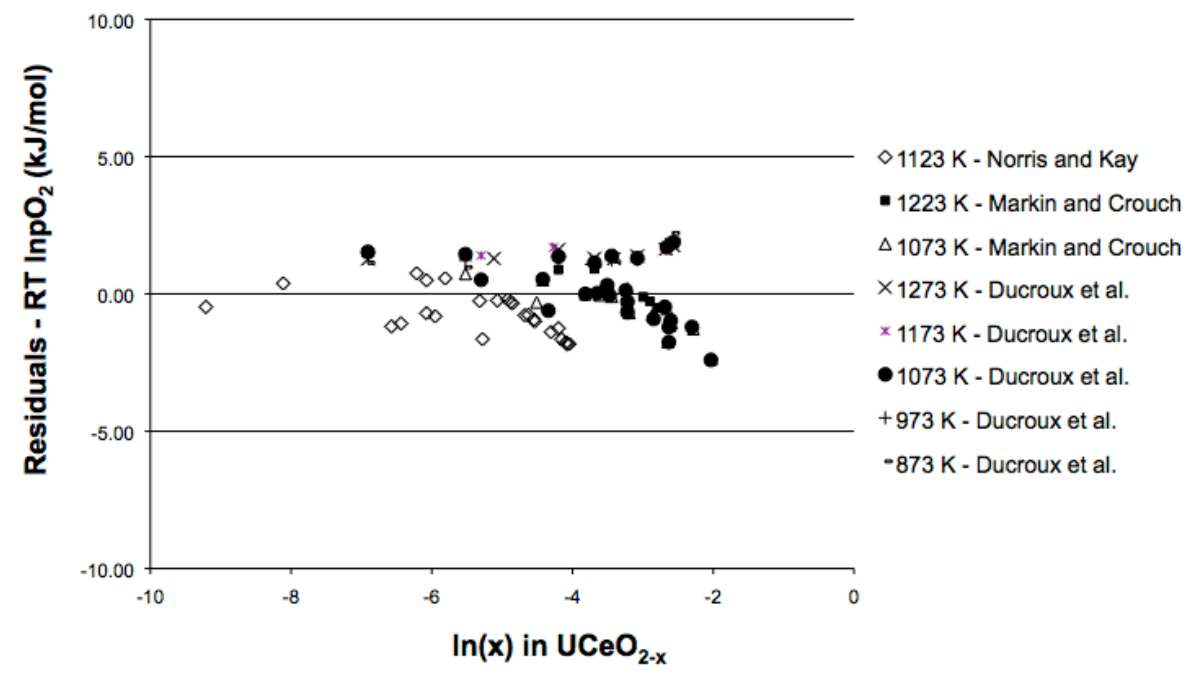

Fig. 4. Residuals for the Markin and Crouch, Norris and Kay, and Ducroux and Baptiste data as compared to the CEF representation.

Results from the initial optimization were converted into a solution database which was imported into FactSage and used to perform thermochemical calculations in the $\mathrm{UCeO}_{2-x}$ system. Figure 5 displays results from a calculation of oxygen potential versus $\mathrm{O}: \mathrm{M}$ for $\mathrm{y}=0.5,0.6,0.7,0.8$ at $1073 \mathrm{~K}$.

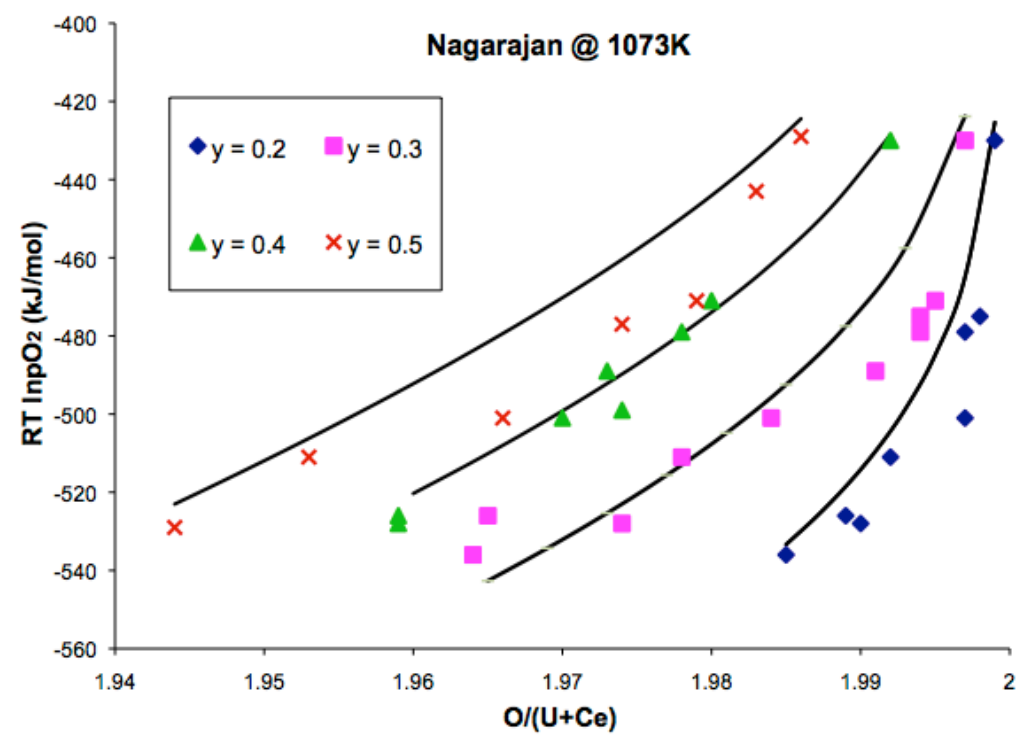

Fig. 5. Comparison of calculation (solid lines) to experimental data from Nagarajan et al. (data points). 
The calculation is compared to experimental data from Nagarajan et al. which was not used in the present optimization due to scatter in the data. The solid lines (without data points) display what may be considered a reasonable smoothing of the experimental data. A similar result can be seen with $\mathrm{U}_{70} \mathrm{Ce}_{30} \mathrm{O}_{2-x}$ data from Nagarajan et al. and Lorrenzelli and Touzelin at 1073, 1173, and 1273 K (Fig. 6). The fit of the calculation to the experimental data is not quite as good as seen in Figure 5 however, the CEF model does reveal the transition into the two phase, miscibility gap region at low O:M. This result is consistent with phase diagram information presented by Nagarajan et al. and Markin and Crouch.

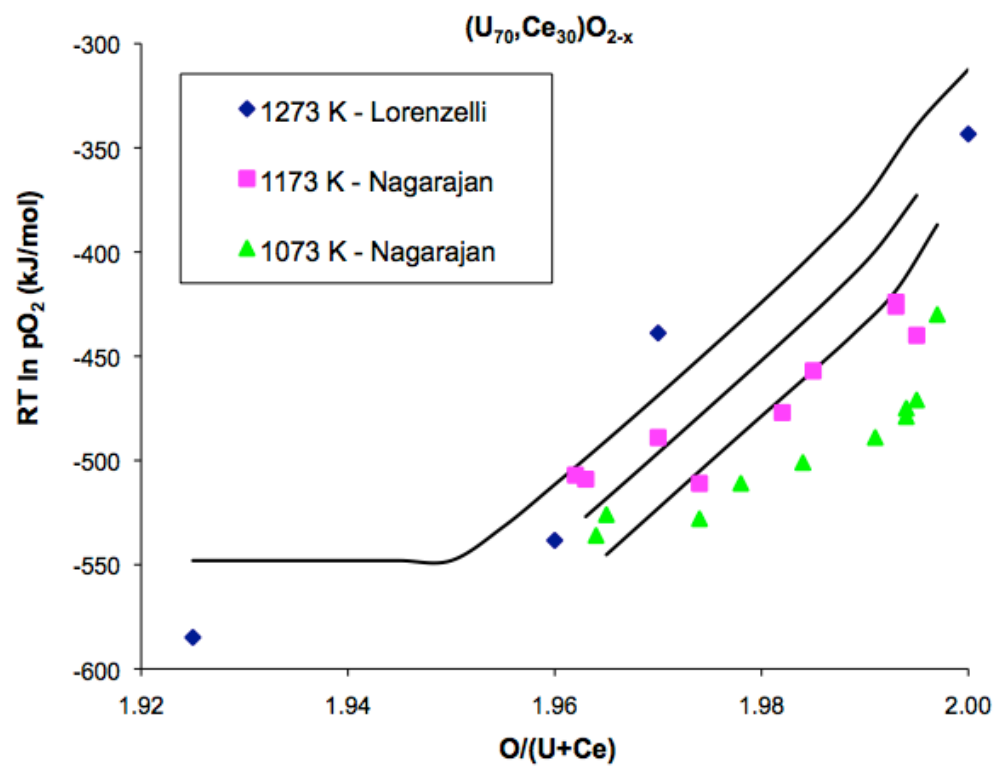

Fig. 6. Comparison of calculation (solid lines) to experimental data from Nagarajan et al. and Lorenzelli and Touzelin (data points).

\section{Conclusions}

The successful representation of the $\mathrm{U}-\mathrm{O}$ and $\mathrm{Ce}-\mathrm{O}$ systems, by Gueneau et al. and Zinkevich et al. respectively, has been extended using the CEF approach to modeling the thermochemical behavior of $\mathrm{UCeO}_{2-x}$. Experimental oxygen potential-temperature-composition data was used to perform an initial optimization of the CEF model, which reproduced the behavior with reasonable accuracy, however, the paucity of experimental data prevented a more precise fit to the data. Future work should include a more critical assessment of the literature data along with a new effort to generate experimental data to support model development and to provide a better description of the evolution of the miscibility gap as a function of composition and temperature. 
'Kleykamp, H., J. Nucl. Mater. 131 (1985) 221

ii Adamson, M.G., et al., J. Nuc. Mater. 130 (1985) 375-392

iii Hillert, M., J. Alloys Compd. 320 (2001) 161-176

iv Gueneau, C., et al., J. Nucl. Mater. 304 (2002) 161

${ }^{\vee}$ Zinkevich, M., et al., Solid State Ionics 177 (2006) 989-1001

${ }^{v i}$ Markin, T.L., Crouch, E., J. Inorg. Nucl. Chem., 32 (1970) 77-82

vii Hoch, M., Furman, F., Thermodynamics, Vol. II, IAEA, Vienna (1965) 517

viii Norris, D., Kay, P., J. Nucl. Mater. 116 (1983) 184-194

ix Ducroux, R., Baptiste, P., J. Nucl. Mater. 97 (1981) 333-336

${ }^{x}$ Lorenzelli, R., Touzelin, B., J. Nucl. Mater. 95 (1980) 290 - 302

${ }^{x i}$ Nagarajan, K., et al., J. Nucl. Mater. 130 (1985) 242-249

xii Bale, C. et al., CALPHAD 26 (2002) 39 